\title{
Characterization of the Pt-Hf-Zr-Ni Thin Film Amorphous Alloys for Precise Optical Glass Lens Mold *
}

\author{
Junpei SAKURAI ${ }^{* *}$, Seiichi HATA ${ }^{* *}$, Ryusuke YAMAUCHI ${ }^{* *}$ \\ and Akira SHIMOKOHBE ${ }^{* *}$ \\ ${ }^{* *}$ Precision and Intelligence Laboratory, Tokyo Institute of Technology \\ 4259 Nagatsuta, Midoriku, Yokohama,.226-8503, Japan \\ E-mail:sakurai.j.aa@m.titech.ac.jp
}

\begin{abstract}
We researched the characteristics of the Pt-Hf-Zr-Ni thin film amorphous alloys for precise optical glass lens mold. The five Pt-Hf-Zr-Ni thin film amorphous alloys having various alloy composition were prepared. Desired characteristics for the glass lens mold were researched. Thus, the $\mathrm{Pt}_{51} \mathrm{Hf}_{20} \mathrm{Zr}_{17} \mathrm{Ni}_{12}$ sample was found as the candidate material for the glass lens mold. This sample showed the crystallization temperature of $994 \mathrm{~K}$, the fractured stress of $1.01 \mathrm{GPa}$ and anti-sticking properties to molten glass. However, since the $\mathrm{Pt}_{51} \mathrm{Hf}_{20} \mathrm{Zr}_{17} \mathrm{Ni}_{12}$ sample exhibited insufficient oxidation resistance, it is necessary to inhibit oxidation with protective coating in order to apply this sample to glass lens mold. Moreover, the $\mathrm{Pt}_{51} \mathrm{Hf}_{20} \mathrm{Zr}_{17} \mathrm{Ni}_{12}$ sample fabricated using alloy target could be cut to taperd shape by the single crystal diamond tools without tool wear.
\end{abstract}

Key words: Thin Film, Amorphous Alloy, Optical Glass Lens Mold

\section{Introduction}

Recently the fabrication of precise optical glass devices, such as pick up lens compatible CD-DVD-Blu-ray disc and diffractive optical elements, has been expected with developing the record density of storage devices. Until now, the hard materials such as tungsten carbide $^{(1),(2)}$ and silicon carbide ${ }^{(3)}$, had been used for the conventional mold material for optical glass devices. However, these materials were too hard to fabricate the precise mold having diffraction grating by machining process. Besides, although many researchers attempt to fabricate the precise mold by the improvement of the machining process ${ }^{(1)-(3)}$, the precise mold for optical glass devices has not been realized yet. Since tungsten carbide was sintered using micro particles of tungsten carbide and binder, it is difficult to fabricate the precise part, such as the sharp edge of the diffractive grating pattern, because of the lack of the micro particles at the precise parts ${ }^{(2)}$.

Amorphous alloys are attractive mold materials for precise optical glass devices because they have a homogeneous and isotropic structure and mold surface used amorphous alloys have no effect on the grains and grain boundaries. Currently, amorphous alloys such as electroless Ni-P plated ${ }^{(4)}$ and Pd-Cu-Si thin film metallic glass ${ }^{(5)}$, have been used for the mold material of optical plastic elements, such as the pick-up lenses compatible with CD DVD ${ }^{(5)}$. Figure 1 shows the schematic of the optical lens mold. These amorphous alloys were plated or sputter-deposited on the surface of blank mold such as hard materials. Thickness of amorphous alloys is approximately $100 \mu \mathrm{m}$. Then only part of the amorphous alloys is cut to precise mold pattern. However, they cannot apply to the mold for the optical glass elements, because crystallization temperatures $T_{\mathrm{x}}$ of these conventional amorphous 


\section{Amorphous alloy \\ (Ni-P plated or PdCuSi TFMG: \\ $\mathrm{t}=100 \mu \mathrm{m}$ )}
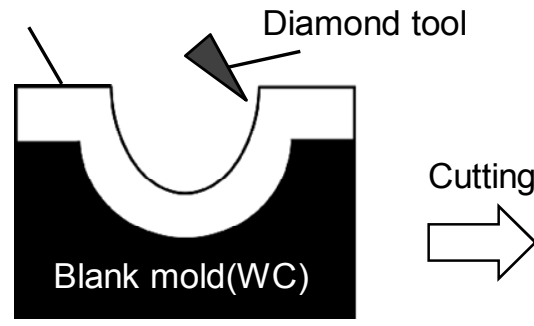

Fig. 1 Fabrication process of precise optical lens mold

alloys are lower than the glass transition temperature $T_{\mathrm{g}}$ of the commonly glasses ${ }^{(6),(7)}$. Moreover, although amorphous Ni-W plated as the candidate material for glass molds was studied, it exhibits the low oxidation resistance ${ }^{(8)}$. In order that the amorphous alloys are applied to the precision mold for optical glass elements, they have to satisfy with the target properties as follow:

(1) High crystallization temperature $T_{\mathrm{x}}$ :

We adopted BK7 (SCHOTT AG) which is a popular glass material for optical glass elements. Since BK7 shows a $T_{\mathrm{g}}$ of $830 \mathrm{~K}{ }^{(8)}, T_{\mathrm{x}}$ of amorphous alloys need to exceed $T_{\mathrm{g}}$ of BK7. Moreover, in order that the molds have the long lifetime, further higher $T_{\mathrm{x}}$ is desirable.

(2) High mechanical strength:

To prevent the precision structure of the mold from being destroyed during molding, the amorphous alloys need to have high compression strength. However, the tensile strength as a measure of the mechanical strength was evaluated instead of the compression strength because it is difficult to measure the compression strength of thin films. Since amorphous alloys are known to be broken during elastic deformation and to do not exhibit plastic strain, the fracture stress, $\sigma_{\mathrm{f}}$, is evaluated during the tensile test, and the target $\sigma_{\mathrm{f}}$ is more than 1.0 GPa.

(3) Sticking property to molten glass:

In order to use amorphous alloys for optical glass elements mold, amorphous alloys need to show an anti-sticking property to molten glass. In this study, the molten glass is dropped to the samples and anti-sticking property is evaluated.

(4) High heat and oxidation resistance:

Since the glass lens molds are used at high molding temperature, the candidate materials are required to have a high heat resistance at least to prevent from crystallization during the molding process. Moreover, if the candidate materials show a high-oxidation resistance, the molding process is carried out in air and then the productivity of glass lens is improved.

(5) Good machinability:

The glass lens molds are fabricating using a diamond cutting-tool in order to obtain fine optical surface. We evaluated the machinability of samples and the machined surface roughness $R_{\mathrm{a}}$. In generally, $R_{\mathrm{a}}$ must be less than $5 \mathrm{~nm}$ in order to obtain practical optical surfaces.

Pt-Hf-Zr-Ni amorphous alloys are promising mold materials for the optical glass elements because these alloys show a good anti-sticking property to molten glass ${ }^{(9),(10)}$. In this work, the alloy compositions of Pt-rich Pt-Hf-Zr-Ni thin film amorphous alloys were selected as the candidate materials. This is because the Pt-rich Pt-Hf-Zr-Ni amorphous alloys are estimated to show the high melting point ${ }^{(11)}$, so that they are expected to show high $T_{\mathrm{x}}$. The characteristics of the Pt-rich Pt-Hf-Zr-Ni thin film amorphous alloys were investigated and the candidate alloy composition of the Pt-Hf-Zr-Ni thin film amorphous 
alloys was searched for optical glass elements mold.

\section{Experimental Methods}

Pt-Hf-Zr-Ni thin film amorphous alloys were prepared using a carousel-type R.F. magnetron sputtering system (L-350S-C, Cannon ANERVA). This system can be used to fabricate samples with various compositions using pure metal targets, rotating substrate holder and by changing RF power for each target ${ }^{(12)}$. Since several alloy targets did not need to be prepared, the cost can reduce. Table 1 shows the sputtering condition for the Pt-Hf-Zr-Ni samples, except for the sample for evaluation of machinability. The sample for evaluation of machinability was fabricated by the same sputtering system using an alloy target. The substrate holder was fixed, so that this sputtering system was used as the conventional parallel-plate type sputtering. This reason is further described in section 3.6 of this paper.

The samples were sputter-deposited on the glass plates for measurement of thickness and composition, $\mathrm{Cu}$ foils for measurement of $T_{\mathrm{x}}$ and mechanical properties, $\mathrm{Al}_{2} \mathrm{O}_{3}$ substrates for evaluation of the heat and oxidation resistance, and $\phi 13 \mathrm{~mm}$ WC substrates for the measurement of sticking property to molten glass and machinability. The $\mathrm{Cu}$ foils were dissolved in $\mathrm{HNO}_{2}+\mathrm{H}_{2} \mathrm{O}(1: 1)$ before measurement of $T_{\mathrm{x}}$ and tensile tests.

The composition of the samples was measured using an energy dispersive X-ray fluorescence spectrometer (EDX, $\mu$ EDX-1300, Shimadzu). The thickness of the samples was measured using a white light interferometer (NewView 5032, Zygo) and was approximately $5 \mu \mathrm{m}$. The phase of as sputter-deposited samples was confirmed to be amorphous using X-ray diffract meter (XRD: RINT-2000, Rigaku). $T_{\mathrm{x}}$ was measured using a thermogravimetric-differential scanning calorimeter (TG-DSC: STA449, NETZSCH) at a heating rate of $0.33 \mathrm{~K} / \mathrm{s}$. Mechanical properties, such as fracture stress $\sigma_{\mathrm{f}}$, were measured by tensile tests at room temperature at a strain rate of $0.0017 \mathrm{~s}^{-1}$ using a thermal mechanical analyzer (TMA-60, Shimadzu).

The sticking properties to molten glass were evaluated by drop tests using BK-7 glass. Figure 2 shows the schematic of the drop tests. This setup was the actual machine for fabrication of glass lens. The samples deposited on the WC substrate were heated to $723 \mathrm{~K}$ in air. The BK7 glass material was melted at 1,273 $\mathrm{K}$ in a crucible above the sample. The molten glass was then dropped on to the sample. The weight of a glass droplet was approximately $50 \mathrm{mg}$, which is roughly the same weight for an assumed typical glass pick-up lens. In the case of fabrication procedure of glass lens, the molten glass on the mold was molding by the compression procedure, though the compression procedure was not carried out in this test. The molten glass droplet contacted the sample, so it was cooled and then changed to a glass piece. The glass piece was removed from the sample by blowing with air. Finally, it was confirmed whether the glass piece stuck to the sample in order to evaluate the sticking properties of molten glass. In each drop test, this cycle was repeated 10 times. The surfaces contacted with molten glass were observed by a scanning electron

Table 1 Sputtering conditions for the Pt-Hf-Zr-Ni samples

\begin{tabular}{|c|c|}
\hline Base pressure & $<5.0 \times 10^{-4} \mathrm{~Pa}$ \\
\hline Ar pressure & $0.5 \mathrm{~Pa}$ \\
\hline Rotation speed of substrate holder & $50 \mathrm{rpm}$ \\
\hline Sputtering time & $5-6 \mathrm{~h}$ \\
\hline Used targets & $\begin{array}{c}\mathrm{Pt}(3 \mathrm{~N}), \mathrm{Zr}(2 \mathrm{~N} \text { up), } \\
\mathrm{Hf}(2 \mathrm{~N} \text { up) and Ni (3N) }\end{array}$ \\
\hline RF power & $\mathrm{Pt}: 118 \mathrm{~W}($ fixed), $\mathrm{Zr}: 50$ to $200 \mathrm{~W}$, \\
& $\mathrm{Hf}: 50$ to $200 \mathrm{~W}$ and Ni 50 to $55 \mathrm{~W}$ \\
\hline
\end{tabular}


microscope (SEM: VE-7800, Keyence) before and after drop tests.

The heat and oxidation resistance were evaluated using XRD. The samples were annealed at $723 \mathrm{~K}$ for various times in the air and vacuum $\left(<1.0 \times 10^{-2} \mathrm{~Pa}\right)$ atmosphere using a muffle kiln and image furnace (MILA-3000, Ulvac technology), respectively.

The machinability of the samples was evaluated by cutting tests using an ultra precision diamond machining system (Nanoform 350, Precitech). Figure 3 shows a schematic of the cutting test setup. The work-piece was the sample deposited on $\phi 13 \mathrm{~mm}$ WC substrates. A work-piece was attached in the work holder. The work-piece was rotated at $500 \mathrm{rpm}$ and was then cut to a tapered shape using a single crystal diamond tool with a $0.5 \mathrm{~mm}$ nose radius, a rake angle of $0^{\circ}$, and a clearance angle of $5^{\circ}$. The radial direction feed was 200 $\mu \mathrm{m} / \mathrm{min}$, the axial direction feed was $200 \mathrm{~nm} / \mathrm{min}$, and the cutting angle (cutting depth / cutting width) was $1 \mu \mathrm{m} / \mathrm{mm}$. The feed start position was at a distance of $3.5 \mathrm{~mm}$ from the rotation center. The feed distance in the radial direction was approximately $3.0 \mathrm{~mm}$. Strictly speaking; diamond tool did not contact the sample surface at the feed start position. The distance between diamond tool and sample surface at the feed start position was less than a few hundred $\mathrm{nm}$. The cut surface was observed using a white light interferometer.

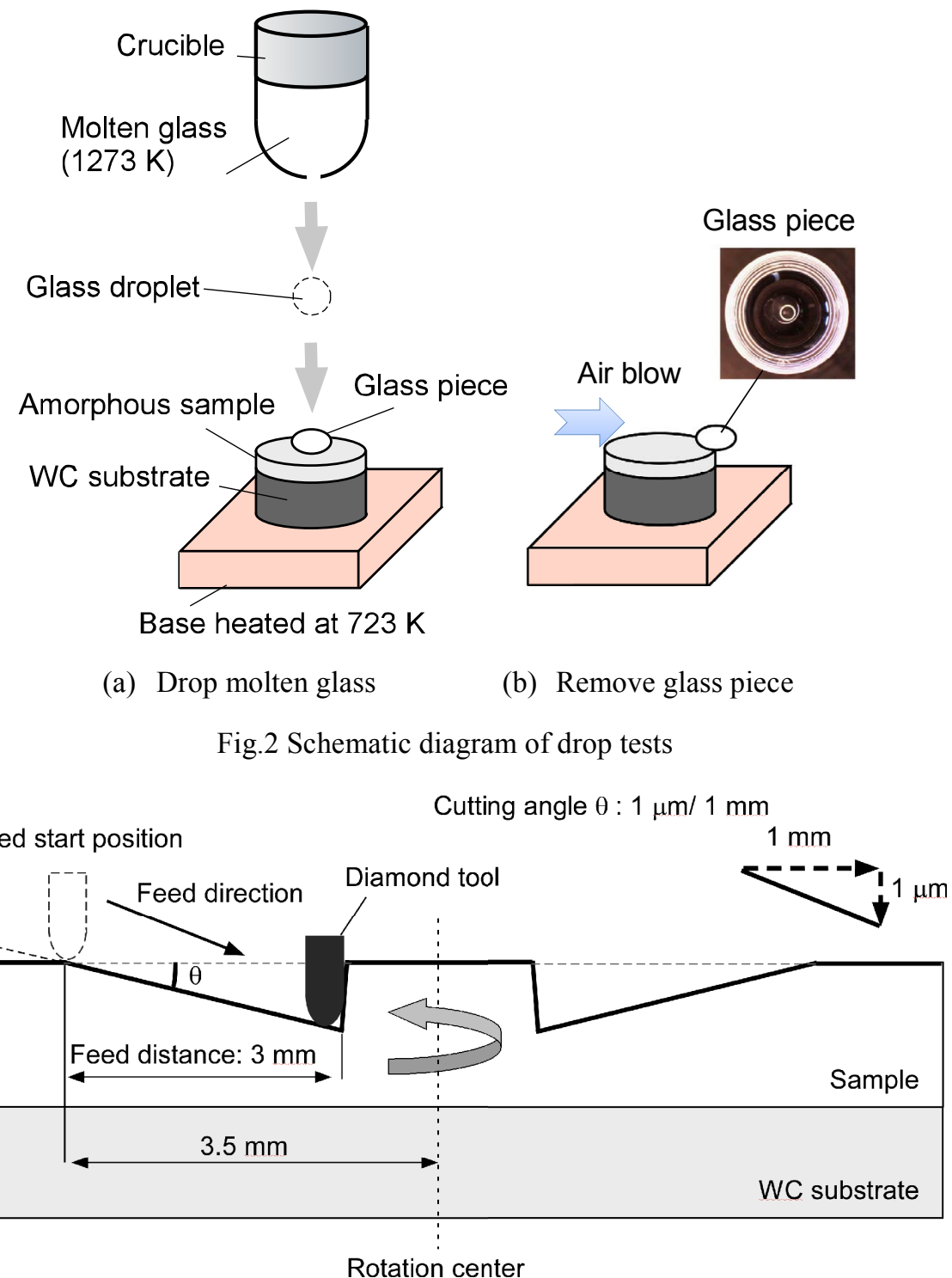

Fig.3 Schematic diagram of cutting tests 


\section{Results and Discussion}

\subsection{Sputter-deposited samples}

To evaluate the various characteristics of the amorphous $\mathrm{Pt}-\mathrm{Hf}-\mathrm{Zr}-\mathrm{Ni}$ samples, typical five amorphous samples $\mathrm{Pt}_{50} \mathrm{Hf}_{\mathrm{x}} \mathrm{Zr}_{40-\mathrm{x}} \mathrm{Ni}_{10}(\mathrm{x}=0,10,20,30$, and 40: at.\%) were sputter-deposited using carousel sputtering. Table 1 shows the RF power of each sample. The compositions of the sputter-deposited samples were confirmed by EDX, were $\mathrm{Pt}_{51} \mathrm{Zr}_{39} \mathrm{Ni}_{10}, \quad \mathrm{Pt}_{51} \mathrm{Hf}_{14} \mathrm{Zr}_{23} \mathrm{Ni}_{12}, \quad \mathrm{Pt}_{51} \mathrm{Hf}_{20} \mathrm{Zr}_{17} \mathrm{Ni}_{12}, \quad \mathrm{Pt}_{52} \mathrm{Hf}_{30} \mathrm{Zr}_{6} \mathrm{Ni}_{12}$ and $\mathrm{Pt}_{52} \mathrm{Hf}_{36} \mathrm{Ni}_{12}$, respectively.

\subsection{Measurement of $\mathrm{T}_{\mathrm{x}}$}

Figure 4 shows the DSC curves for crystallization of the amorphous Pt-Hf-Zr-Ni samples. $\mathrm{Pt}_{51} \mathrm{Zr}_{39} \mathrm{Ni}_{10}$ sample showed the one endothermic peak was observed and $T_{\mathrm{x}}$ was $934 \mathrm{~K} . T_{\mathrm{x}}$ increased with increasing Hf-content and $T_{\mathrm{x}} \mathrm{s}$ were $942 \mathrm{~K}$ for the $\mathrm{Pt}_{51} \mathrm{Hf}_{14} \mathrm{Zr}_{23} \mathrm{Ni}_{12}$ sample, and $994 \mathrm{~K}$ for the $\mathrm{Pt}_{51} \mathrm{Hf}_{20} \mathrm{Zr}_{17} \mathrm{Ni}_{12}$ sample and 1,018 $\mathrm{K}$ for $\mathrm{Pt}_{52} \mathrm{Hf}_{30} \mathrm{Zr}_{6} \mathrm{Ni}_{12}$ sample. When $\mathrm{Hf}$ substituted for $\mathrm{Zr}$ completely, the $\mathrm{Pt}_{52} \mathrm{Hf}_{36} \mathrm{Ni}_{12}$ sample showed $T_{\mathrm{x}}$ of $980 \mathrm{~K}$.

\subsection{Mechanical properties}

Figure 5 shows the stress-strain curves of the amorphous Pt-Hf-Zr-Ni samples. All samples were fractured during elastic deformation. The $\mathrm{Pt}_{51} \mathrm{Zr}_{39} \mathrm{Ni}_{10}$ sample showed the superior mechanical properties, and the fracture stress $\sigma_{\mathrm{f}}$, fracture strain $\varepsilon_{\mathrm{f}}$, and Young's modulus $E$ were $1.44 \mathrm{GPa}, 1.93 \%$, and $77.1 \mathrm{GPa}$, respectively. $\sigma_{\mathrm{f}}$ decreased with increasing the Hf-content. The $\mathrm{Pt}_{51} \mathrm{Hf}_{14} \mathrm{Zr}_{23} \mathrm{Ni}_{12}$ and $\mathrm{Pt}_{51} \mathrm{Hf}_{20} \mathrm{Zr}_{17} \mathrm{Ni}_{12}$ sample showed the $\sigma_{\mathrm{f}}$ of 1.08 and $1.01 \mathrm{GPa}$, respectively. Further increasing Hf-content, the samples were brittle and $\sigma_{\mathrm{f}}$ was $0.32 \mathrm{GPa}$ for $\mathrm{Pt}_{52} \mathrm{Hf}_{30} \mathrm{Zr}_{6} \mathrm{Ni}_{12}$ sample, and $0.30 \mathrm{GPa}$ for $\mathrm{Pt}_{52} \mathrm{Hf}_{36} \mathrm{Ni}_{12}$ sample. As the results

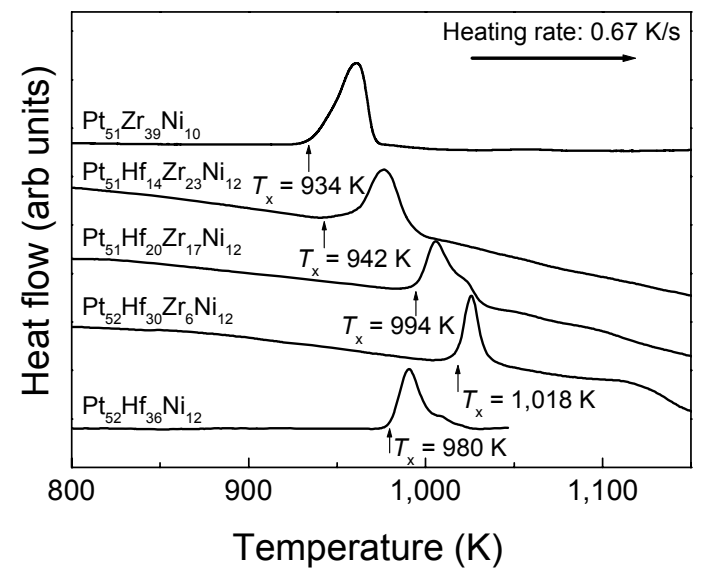

Fig.4 DSC curves for crystallization of the amorphous Pt-Hf-Zr-Ni samples.

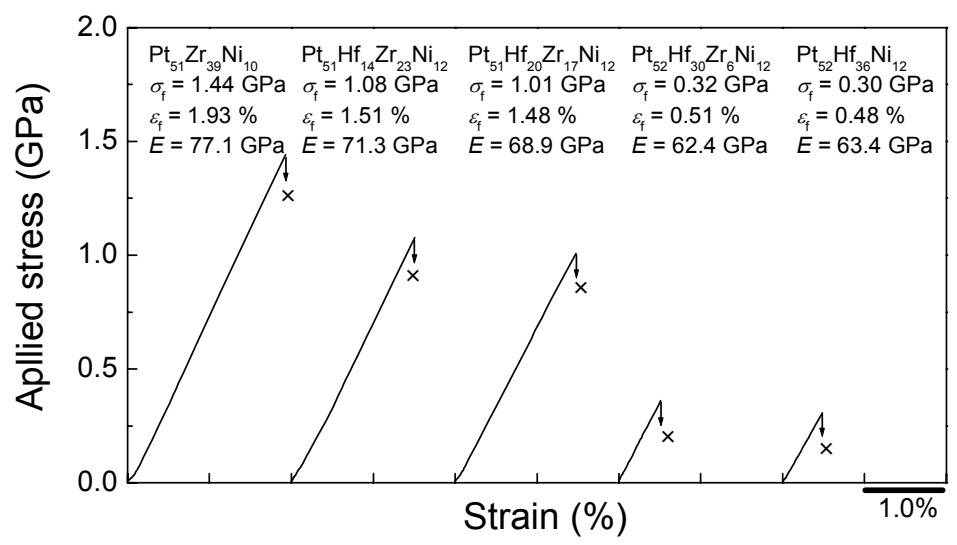

Fig.5 S-S curves of the Pt-Hf-Zr-Ni samples 
of tensile tests, the $\mathrm{Pt}_{51} \mathrm{Zr}_{39} \mathrm{Ni}_{10}, \mathrm{Pt}_{51} \mathrm{Hf}_{14} \mathrm{Zr}_{23} \mathrm{Ni}_{12}$ and $\mathrm{Pt}_{51} \mathrm{Hf}_{20} \mathrm{Zr}_{17} \mathrm{Ni}_{12}$ samples satisfied the target $\sigma_{\mathrm{f}}$.

\subsection{Sticking properties to molten glass}

After the drop tests, all samples did not stick to molten glass and cooled glass pieces could be removed from all the samples by only blowing air. Figures 6 show the SEM images of the (a) $\mathrm{Pt}_{51} \mathrm{Zr}_{39} \mathrm{Ni}_{10}$, (b) $\mathrm{Pt}_{51} \mathrm{Hf}_{20} \mathrm{Zr}_{17} \mathrm{Ni}_{12}$ samples before and after drop tests. Both samples before drop tests show the granular microstructure. This structure corresponded to the columnar structure originating from sputter-deposited under the certain conditions such as low sputtering rate and high Ar pressure during sputtering ${ }^{(13)}$. The granular structure size ranged from a few hundred $\mathrm{nm}$ to a few micrometers. The surface roughness $R_{\mathrm{a}}$ of both samples before drop tests was $1 \mathrm{~nm}$.

In the $\mathrm{Pt}_{51} \mathrm{Zr}_{39} \mathrm{Ni}_{10}$ sample after the drop tests as shown Fig. 6(a), there were many of the white dots. It is considered that these dots were the glass materials stuck during the drop tests. In the $\mathrm{Pt}_{51} \mathrm{Hf}_{20} \mathrm{Zr}_{17} \mathrm{Ni}_{12}$ samples after the drop tests as shown Fig. 6(b), there was no white dot. Thus, this sample showed the good anti-sticking properties to molten glass. $R_{\mathrm{a}}$ of both samples after drop tests remained to be $1 \mathrm{~nm}$. However, if the number of drop tests increases, it is predicted that $R_{\mathrm{a}}$ of the $\mathrm{Pt}_{51} \mathrm{Zr}_{39} \mathrm{Ni}_{10}$ sample became larger than that of the $\mathrm{Pt}_{51} \mathrm{Hf}_{20} \mathrm{Zr}_{17} \mathrm{Ni}_{12}$ sample. As the results of DSC, tensile tests and drop test, $\mathrm{Pt}_{51} \mathrm{Hf}_{20} \mathrm{Zr}_{17} \mathrm{Ni}_{12}$ sample was suitable alloy composition among evaluated samples.

\subsection{Heat and oxidation resistance}

Figure 7 shows the XRD profiles of the as-sputtered $\mathrm{Pt}_{51} \mathrm{Hf}_{20} \mathrm{Zr}_{17} \mathrm{Ni}_{12}$ sample and $\mathrm{Pt}_{51} \mathrm{Hf}_{20} \mathrm{Zr}_{17} \mathrm{Ni}_{12}$ sample annealed at $723 \mathrm{~K}$ for $20 \mathrm{~h}$ in air atmosphere. As-sputter-deposited sample showed a halo pattern as typical amorphous sample. The sample annealed at $723 \mathrm{~K}$ for $20 \mathrm{~h}$ showed the $\mathrm{ZrO}_{2}$ peak around $30^{\circ}$ and the Pt peak around $40^{\circ}$. Since the half bandwidth of Pt peak was wide, this sample was not crystallized completely. Altough $T_{\mathrm{x}}$ of this sample was $994 \mathrm{~K}$ and it was assumed to be sufficient high $T_{\mathrm{x}}$ for glass molding, this sample was started to crystalize by annealing at $723 \mathrm{~K}$ for $20 \mathrm{~h}$ in air atmosphere. Figure 8

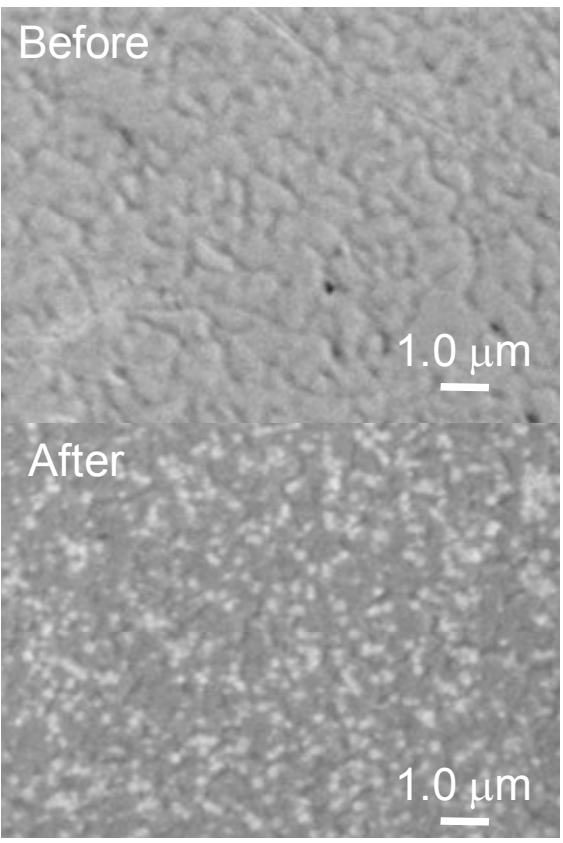

(a) $\mathrm{Pt}_{51} \mathrm{Zr}_{39} \mathrm{Ni}_{10}$

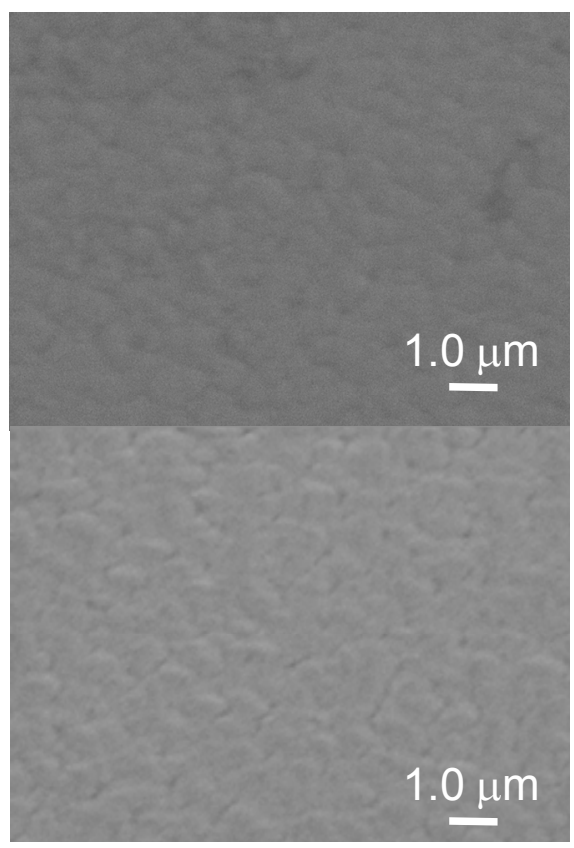

(b) $\mathrm{Pt}_{51} \mathrm{Hf}_{20} \mathrm{Zr}_{17} \mathrm{Ni}_{12}$

Fig.6 SEM images of the (a) $\mathrm{Pt}_{51} \mathrm{Zr}_{39} \mathrm{Ni}_{10}$, (b) $\mathrm{Pt}_{51} \mathrm{Hf}_{20} \mathrm{Zr}_{17} \mathrm{Ni}_{12}$ samples before and after drop tests 
shows the XRD profiles of the $\mathrm{Pt}_{51} \mathrm{Hf}_{20} \mathrm{Zr}_{17} \mathrm{Ni}_{12}$ sample annealed at $723 \mathrm{~K}$ for varous hours in vacuum atmosphere. As-sputter-deposited sample also showed a halo pattern as typical amorphous sample. Unlike the sample annealed at $723 \mathrm{~K}$ for $20 \mathrm{~h}$ in air as shown in Fig. 8, the sample annealed at $723 \mathrm{~K}$ for $20 \mathrm{~h}$ showed the amorphous halo and the $\mathrm{ZrO}_{2}$ peak. This $\mathrm{ZrO}_{2}$ was formed by residual oxygen in the furnace. When annealing time was $50 \mathrm{~h}$, several sharp peaks coressponding to $\mathrm{Pt}$ and $\mathrm{ZrO}_{2}$ were obsereved. Thus, this sample was crystallized.

From both XRD results, it was considered that the oxidation resistance of this sample was insufficeint. During annealing in air and vacuum, the oxidation of the sample was started at first, and then Pt was crystallized subsequently. In the Pt-rich Pt-(Hf-Zr)-Ni pseudo ternary alloy system, amorphous composition region was narrow and Pt-content ranged from 50 to 60 at. $\%{ }^{(9),(10)}$. $\mathrm{Zr}$ in the matrix was easy to oxdize and $\mathrm{ZrO}_{2}$ was formed. Alloy composition of $\mathrm{Zr}$ decreased with progressing $\mathrm{Zr}$ oxidation. Thus, alloy composition of Pt increased and Pt was crystallized.

To block the oxidation of the sample, the samples was coated with $\mathrm{Cr}$ thin film using the sputtering. The $\mathrm{Cr}$ was included in the protective coatings for conventional glass lens mold because $\mathrm{Cr}$ passivates and inhibits the oxidation. Figure 9 shows the XRD profiles of the $\mathrm{Pt}_{51} \mathrm{Hf}_{20} \mathrm{Zr}_{17} \mathrm{Ni}_{12}$ samples coated with $\mathrm{Cr}$ thin film, annealed at $723 \mathrm{~K}$ for varous hours in vacuum. Thickness of $\mathrm{Cr}$ thin film was $100 \mathrm{~nm}$. The large peak at $43^{\circ}$ coresponded to $\mathrm{Cr}$ thin film. All samples showed amorphous halo, $\mathrm{Cr}$ peak and no $\mathrm{ZrO}_{2}$ peak. The sample annealed at $723 \mathrm{~K}$ for $100 \mathrm{~h}$, the sample reamined amorphous state. These XRD results

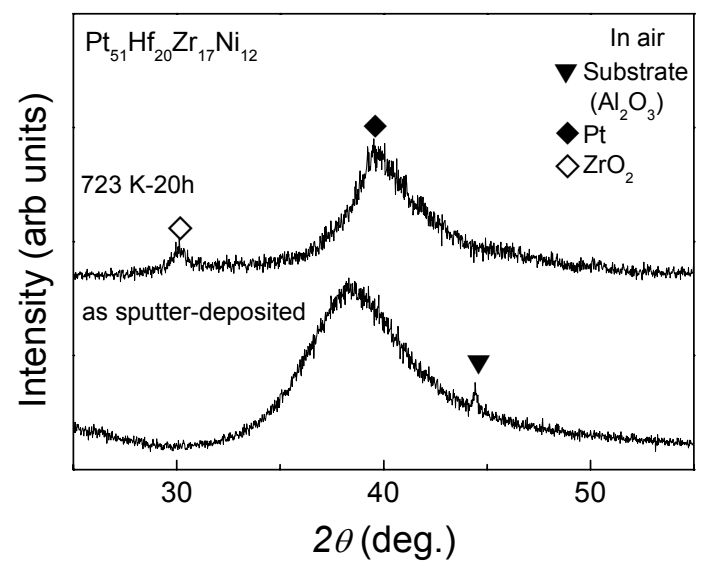

Fig. 7 XRD profiles of the as-sputtered $\mathrm{Pt}_{51} \mathrm{Hf}_{20} \mathrm{Zr}_{17} \mathrm{Ni}_{12}$ sample and $\mathrm{Pt}_{51} \mathrm{Hf}_{20} \mathrm{Zr}_{17} \mathrm{Ni}_{12}$ sample annealed at $723 \mathrm{~K}$ for $20 \mathrm{~h}$ in air atmosphere

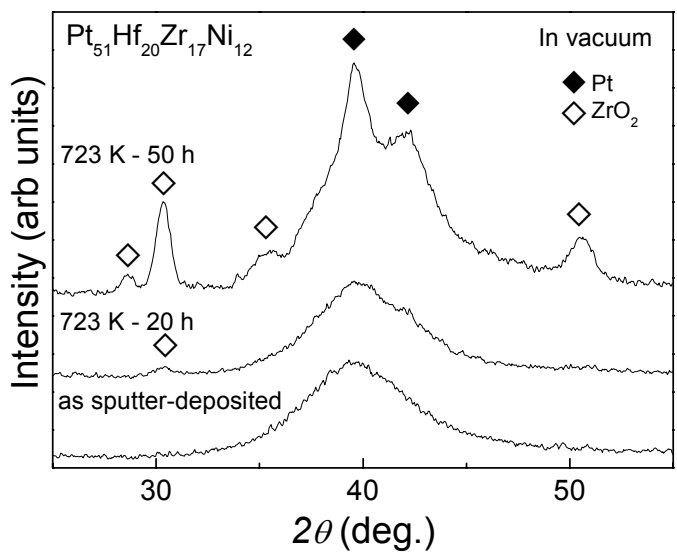

Fig. 8 XRD profiles of the $\mathrm{Pt}_{51} \mathrm{Hf}_{20} \mathrm{Zr}_{17} \mathrm{Ni}_{12}$ sample annealed at $723 \mathrm{~K}$ for various time in vacuum atmosphere 


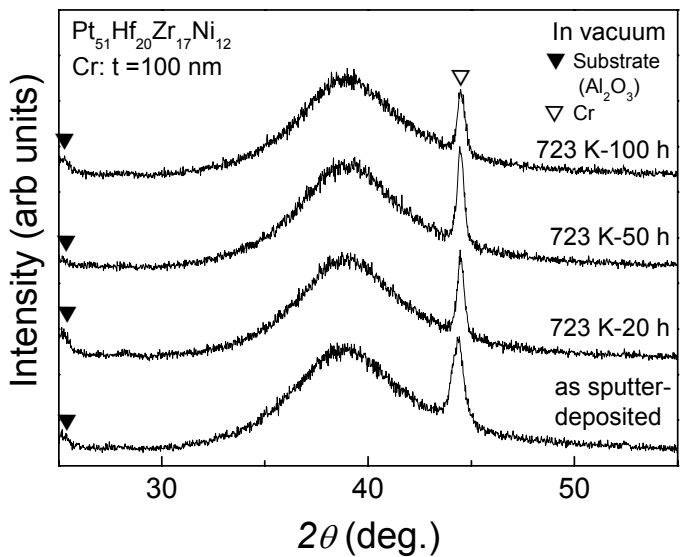

Fig. 9 XRD profiles of the $\mathrm{Pt}_{51} \mathrm{Hf}_{20} \mathrm{Zr}_{17} \mathrm{Ni}_{12}$ samples coated with $\mathrm{Cr}$ thin film, annealed at $723 \mathrm{~K}$ for varous hours in vacuum

indicated that the $\mathrm{Pt}_{51} \mathrm{Hf}_{20} \mathrm{Zr}_{17} \mathrm{Ni}_{12}$ sample was enabled to be used for glass lens mold by inhibition of oxidation. However, it is considered that the use of protective coatings is not the best method to inhibit oxidation because they change the surface shape of mold. In the further works, we have to search for Pt-based thin film amorphous alloys that have high oxidation resistance or passivate themselves in order to inhibit mold oxidation.

\subsection{Machinability}

To evaluate the machinability of the $\mathrm{Pt}_{51} \mathrm{Hf}_{20} \mathrm{Zr}_{17} \mathrm{Ni}_{12}$ sample, the sample was sputter-deposited using a $\mathrm{Pt}_{51} \mathrm{Hf}_{20} \mathrm{Zr}_{17} \mathrm{Ni}_{12}$ alloyed target. Since the samples fabricated by the carousel sputtering system have the columnar structure as shown in Fig. 6, their machinability was inferior to that of the sample fabricated using alloy target ${ }^{(10)}$. Table 2 shows the sputter condition for this sample.

Figure 10 shows the cutting profile of the $\mathrm{Pt}_{51} \mathrm{Hf}_{20} \mathrm{Zr}_{17} \mathrm{Ni}_{12}$ sample fabricated using alloy target. This sample could be cut into tapered shape. The total cutting width in the radial direction was $1.79 \mathrm{~mm}$ and the total cutting depth in the axial direction was $1.19 \mu \mathrm{m}$. The total cutting width was shorter than the feed distance of $3.00 \mathrm{~mm}$ because of the initial gap

Table 2 Sputtering conditions for the $\mathrm{Pt}_{51} \mathrm{Hf}_{20} \mathrm{Zr}_{17} \mathrm{Ni}_{12}$ sample using alloy target

\begin{tabular}{|c|c|}
\hline Base pressure & $<5.0 \times 10^{-4} \mathrm{~Pa}$ \\
\hline Ar pressure & $0.5 \mathrm{~Pa}$ \\
\hline Sputtering time & $8.5 \mathrm{~h}$ \\
\hline Used targets & $\mathrm{Pt}_{51} \mathrm{Hf}_{20} \mathrm{Zr}_{17} \mathrm{Ni}_{12}$ (at.\%) \\
\hline RF power & $150 \mathrm{~W}$ \\
\hline
\end{tabular}

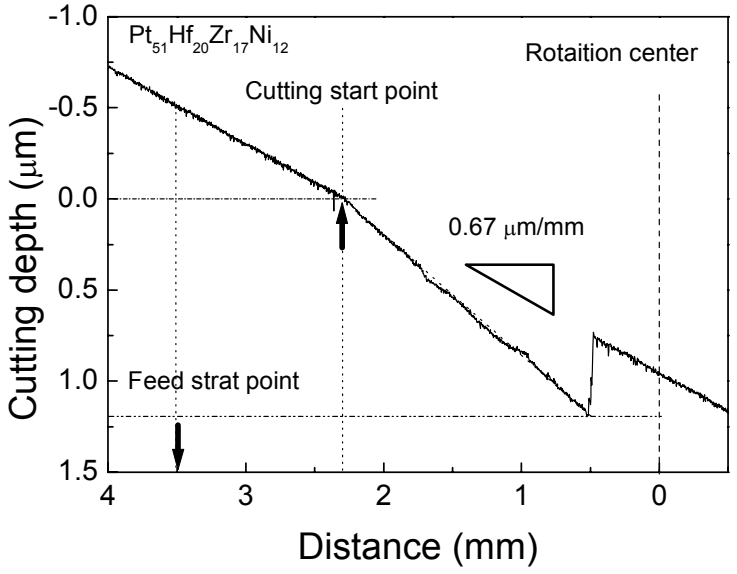

Fig. 10 Cutting profile of the $\mathrm{Pt}_{51} \mathrm{Hf}_{20} \mathrm{Zr}_{17} \mathrm{Ni}_{12}$ sputter-deposited thin films 
between the diamond tool and sample surface. The cutting angle was $0.67 \mu \mathrm{m} / \mathrm{mm}$ (cutting depth / cutting width: $1.19 \mu \mathrm{m} / 1.79 \mathrm{~mm}$ ) and it was smaller than the aimed cutting condition $(=1.0 \mu \mathrm{m} / \mathrm{mm})$. Figures 11 show (a) surface profile and (b) image of cutting surface around the feed end position. Surface roughness $R_{\mathrm{a}}$ (arithmetic mean deviation of the profile) was $5 \mathrm{~nm}$ and cutting surface was obtained to use for optical surface as shown in Fig. 11(b).

Figure 12 shows the SEM image of the rake face of diamond tool after the cutting test. Tool wear and cutting edge chipping was not recognized. Therefore, the reason why the cutting angle was smaller than cutting condition was not caused by the tool wear and cutting edge chipping. In this cutting test, since the wrok piece was cut to a tapered shape with samll cutting angle $(1.0 \mu \mathrm{m} / \mathrm{mm})$, cutting force was insufficient. Thus, cutting angle was smaller than cutting condition.

In this paper, since the machinabillity of the $\mathrm{Pt}_{51} \mathrm{Hf}_{20} \mathrm{Zr}_{17} \mathrm{Ni}_{12}$ sample might be scant in this cutting test, we have to optimize the cutting conditions for this sample. However, we indicated the possibility that Pt-based amorphous alloys are used as the material for precise optical glass mold. In future works, we have to search for the Pt-based thin film amorphous alloys that exhibit high oxidation resistance and machinability by the changing alloy composition.

\section{Conclusion}

We investigated the characteristics of the Pt-Hf-Zr-Ni thin film amorphous alloys for precise glass lens mold. Five Pt-rich Pt-Hf-Zr-Ni thin film amorphous alloys were prepared by the carousel sputter system and their characteristics were investigated. Thus, the
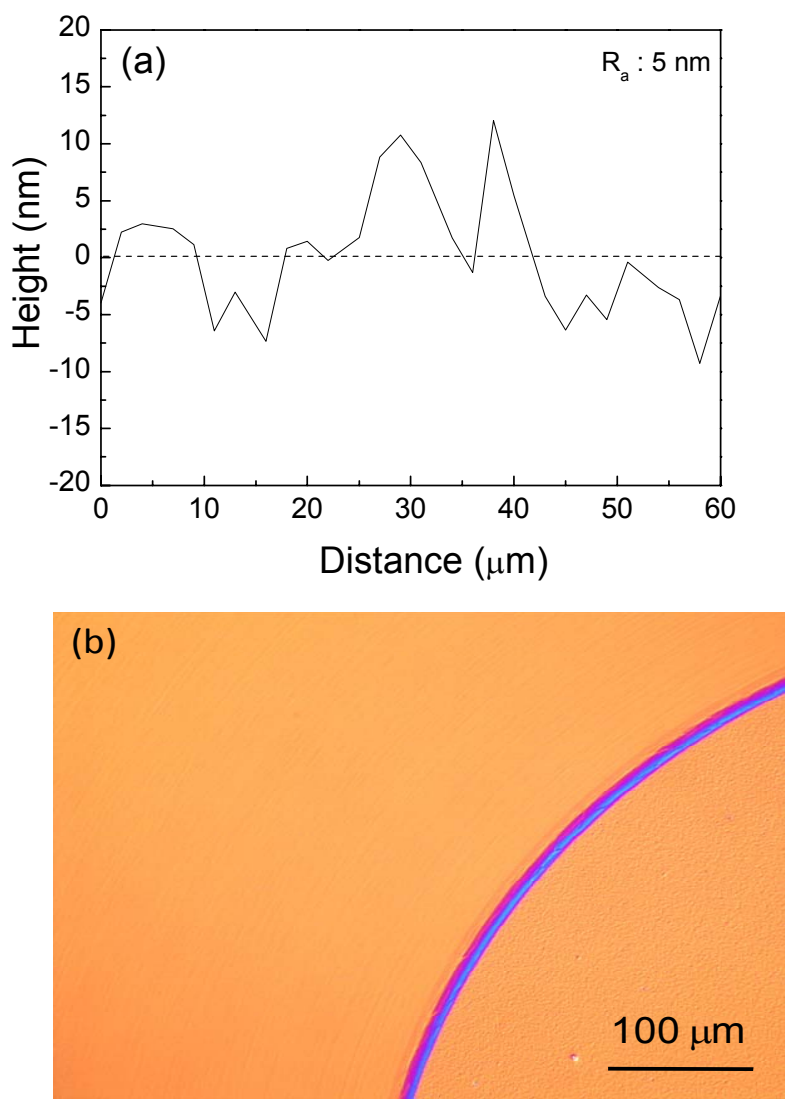

Fig. 11 (a) Surface profile and (b) image of cutting surface around the feed end position of the $\mathrm{Pt}_{51} \mathrm{Hf}_{20} \mathrm{Zr}_{17} \mathrm{Ni}_{12}$ sputter-deposited thin film 


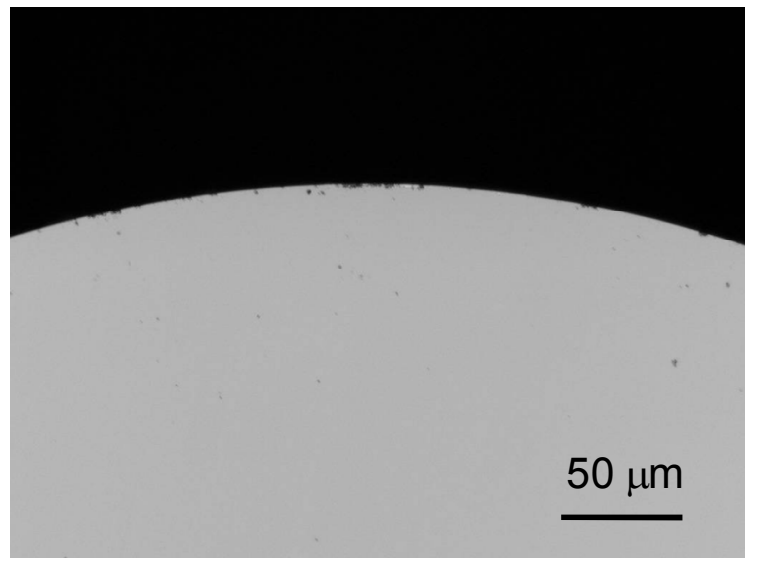

Fig. 12 SEM image of the rake face of diamond tool after the cutting test

$\mathrm{Pt}_{51} \mathrm{Hf}_{20} \mathrm{Zr}_{17} \mathrm{Ni}_{12}$ sample was found as glass lens mold material. This sample showed the $T_{\mathrm{x}}$ of $994 \mathrm{~K}$, the $\sigma_{\mathrm{f}}$ of $1.01 \mathrm{GPa}$ and anti-sticking properties. Moreover, the $\mathrm{Pt}_{51} \mathrm{Hf}_{20} \mathrm{Zr}_{17} \mathrm{Ni}_{12}$ sample fabricated using alloy target could be cut by the diamond tools without tool wear However, the $\mathrm{Pt}_{51} \mathrm{Hf}_{20} \mathrm{Zr}_{17} \mathrm{Ni}_{12}$ sample was enabled to be used for glass lens mold by inhibition of oxidation.

From these results, we indicated that Pt-based amorphous alloys are used as the material for precise optical glass mold. In the further works, we have to search for Pt-based thin film amorphous alloys that have high oxidation resistance or passivate themselves in order to inhibit mold oxidation. Moreover, the machinability is modified by the changing the alloy system.

\section{Acknowledgment}

This research was supported by the Japan Society for the Promotion of Science (JSPS) Grants-in-Aid for Young Scientists (B) (197604886) 2007-2008. Experiments were carried out using equipment in the Installations for Nanomechatronics Research and the Center for Advanced Materials Analysis at the Tokyo Institute of Technology. We thank Prof. Hosoda at Tokyo institute of Technology for the DSC measurement and Konica Minolta Opto for the drop tests and cutting tests.

\section{References}

(1) Yuji Yamamoto, Hirofumi Suzuki, Takashi Onishi, Tadashi Okino and Toshimichi Moriwaki, Precision grinding of microarray lens molding die with 4-axes controlled microwheel, Sci. Tech. Advanced Mat., vol.8, No.3 (2007) pp.173-176.

(2) Taichi Fujii, Minoru Hirano, Tetsuro Shibukawa, Tohru Ishida and Yoshimi Takeuchi, Study on Precision Machining of Glass Lens Mold with Minute Structure, J. Jpn. Soc.

Precision Eng. Vol.74, No.12 (2008) pp. 1298-1302 (in Japanese).

(3) Toru Itoh, Shuji Tanaka, Jing-Feng Li, Ryuzo Watanabe, Masayoshi Esashi, Silicon Carbide Microfabrication by Silicon Lost Molding for Glass-Press Molds, $J$. Microelectromechanical Systems, vol.15, No.14 (2006) pp. 859-863.

(4) A. Pramanik, K.S. Neo, M. Rahman, X.P. Li, M. Sawa, and Y. Maeda, Cutting performance of diamond tools during ultra-precision turning of electroless-nickel plated die materials, J. Mater. Process. Technol., vol.140, (2003) pp. 308-313.

(5) J. Sakurai, S. Hata, and A. Shimokohbe, Characteristics of Thin Film Metallic Glass for MEMS and Precise Part, Proc. Second TIT-BIT Joint Work Shop on Mech. Eng., (2007-8), pp. $62-67$. 
(6) K.G. Keong, W. Sha, and S. Malinov, Crystallisation kinetics and phase transformation behaviour of electroless nickel-phosphorus deposits with high phosphorus content, $J$. Alloys Compounds, vol. 334, (2002) pp. 192-199.

(7) R. Yamauchi, S. Hata, J. Sakurai and A. Shimokohbe: Jpn. Combinatorial Search for Low Resistivity PdCuSi Thin Film Metallic Glass, Jpn. J. Appl. Phys., vol.45, No.4 (2006) 5911-5919.

(8) Manabu YASUI, Masaharu TAKAHASHI, Satoru KANEKO, Tomoyuki TSUCHIDA, Yasuo HIRABAYASHI, Kohichi SUGIMOTO, Jun-ichi UEGAKI, and Ryutaro MAEDA, Micro Press Molding of Borosilicate Glass Using Plated Ni-W Molds, Jpn. J. Appl. Phys., vol.46, No.9B, (2007) pp. 6378-6381.

(9) J. C. Lambropoulos, T. Fang, P. D. Funkenbusch, S. D. Jacobs, M. J. Cumbo, and D. Golini, Surface microroughness of optical glasses under deterministic microgrinding, Appl. Opt, vol.35, No.22, (1996) pp. 4448-4462.

(10) Seiichi HATA, Junpei SAKURAI, and Akira SHIMOKOHBE, Experimental fabrication of glass lens molding die made of novel Pt based amorphous alloy, Trans. of the Japan Society of Mechanical Engineers, Series C, vol.74, No.4, (2008), pp.1020-1025 (in Japanese).

(11) Junpei Sakurai, Seiichi Hata, Ryusuke Yamauchi, Hiroyuki Tachikawa, Akira Shimokohbe, Combinatorial Searching for Noble Metal-based Amorphous Alloy Thin Films for Glass Lens Mold, MRS Proc., 1024E, (2007-11-) A 01-06.

(12) T. B. Massalski ed., Binary Alloy Phase Diagram (second edition.) Vol.3, (1990) p.1925, Material Information Soc.

(13) J. Sakurai, S. Hata, and A. Shimokohbe, Characteristics of Cu-Zr Thin Film Metallic Glasses Fabricated by a Carousel-Type Sputtering System, Jpn. J. Appl. Phys., vol.48, No.2 (2009) 025503.

(14) S. Miyazaki and A. Ishida, Martensitic transformation and shape memory behavior in sputter-deposited TiNi-base thin films, Mater. Sci. Eng. A, Vol. 273-275 (1999) pp.106-133. 